\title{
Effect of Grain Shape and Pre-soaking on Cooking Time and Cooking Energy
}

\author{
K.G. Gunasekara and D.A.N. Dharmasena ${ }^{1 *}$ \\ Postgraduate Institute of Agriculture \\ University of Peradeniya \\ Sri Lanka
}

\begin{abstract}
Rice is the staple food of Sri Lankans with a per capita rice consumption of approximately $114 \mathrm{~kg} /$ year in 2010. Parboiled rice is gaining more popularity among Sri Lankans as it is healthier than raw rice. Households spend much of their energy on cooking, and parboiled rice consumes more energy than raw rice. A slender (Bg 94-1) and a medium (Bg 360) shaped rice varieties were selected and the optimum soaking duration was calculated using the Peleg's model. The optimum rice to water ratio was determined by cooking rice samples in a rice cooker till no opaque core was observed when pressed between two glass plates. A two factor factorial experiment was carried out to determine the cooking time and energy required for cooking considering the grain type and the precook condition (soaked, and un-soaked) using an electric rice cooker and a digital watt meter. The optimum soaking duration was found to be $150 \mathrm{~min}$ for $\mathrm{Bg} 94-1$ and $44 \mathrm{~min}$ for $\mathrm{Bg} 360$. The optimum rice: water ratio for cooking both rice varieties was 1:2.5. The main effect of both factors was significant $(p<0.05)$ while the interaction was not significant $(p \geq 0.05)$ for both cooking energy and cooking time. Medium shaped rice variety required $18 \%$ less cooking time compared to slender rice variety. Moreover, the energy spent for cooking of medium variety was $19 \%$ less than that of the slender variety. Further, pre-soaking of grains up to $86 \%$ saturation was found to reduce cooking energy and time by 17 and $18 \%$, respectively.
\end{abstract}

Key words: Energy, Grains, Peleg's model, Pre-cook, Rice.

\section{INTRODUCTION}

Rice was first differentiated from a grass progenitor in Godwanaland supercontinent more than 130 million years ago. Asian cultivars of rice was first domesticated in the Yangtze River valley, in China (Vaughan et al., 2008). The cultivation was spread through Asia up to 137, 936,500 ha in 2000 (Nguyen, 2002). As the staple food, rice currently contributes more than $40 \%$ of the calorie consumption of most Asians (IRRI, 2008). Subsequently, the global rice consumption and residual component is projected to be 391.99 million tonnes in 2008/09 (Childs, 2009). However under Sri Lankan context, it has been reported that the average annual per-capita rice consumption in 1950's, 1960's and 1970's were 92.9, 100.6, and 96.8 $\mathrm{kg}$, respectively. (Ameresekere, 1984), and it was further increased up to $100 \mathrm{~kg}$ in 2000 , $108 \mathrm{~kg}$ in 2008, and predicted to be $116 \mathrm{~kg}$ in 2010. (Department of Agriculture, 2008)

\footnotetext{
To whom correspondence should be addressed: dand@pdn.ac.lk

Department of Agricultural Engineering, University of Peradeniya, Peradeniya, Sri Lanka
} 
The consumer preference shows a spatial distribution; shorter grain varieties known as Samba are more popular in the central and western part of the country while the longer varieties known as Nadu are preferred in eastern part of the country. This differentiation is mainly due to the eating quality of cooked rice, which is directly influenced by the shape and size of the rice grains. The basic dimension used for the rice grain classification is size (length of the grain) and the shape (Length/width ratio). Both USDA and FAO classification systems are used by scientists. There are four classes defined according to the grain length as Extra Long (More than $7.6 \mathrm{~mm}$ according to the USDA classification, and more than $7 \mathrm{~mm}$ according to the FAO classification), Long (6.61-7.50 $\mathrm{mm}$ according to the USDA classification and 6.0-7.0 mm according to the FAO classification), Medium (5.51-6.60 mm according to the USDA classification and 5.0-5.9 $\mathrm{mm}$ according to the FAO classification) and Short (Less than $5.51 \mathrm{~mm}$ according to the USDA classification, and less than $5.0 \mathrm{~mm}$ according to the FAO classification). According to the length to width ratio, rice grains are classified into three categories such as, Slender (more than 3 according to both the classifications), Medium (2.1-3.0 according to USDA classification and 2.4-3.0 according to FAO classification) Bold (less than 2.1 according to USDA classification and 2.0-2.39 according to FAO classification) and Round (less than 2.0, according to FAO classification).

Not only the different grain varieties, however, parboiled rice too has been gaining increasing consumer preference in Sri Lanka, especially in the upcountry region by accounting for $55 \%$ of the market in all the districts in the region (Weligamge, 2003). Parboiling, the hydrothermal treatment which involves soaking, heat treatment, and drying which are carried out prior to the milling process, is found to increase the quality of processed rice. During parboiling, the paddy is soaked for 36-48 $\mathrm{h}$ in ambient temperature or for 2-4 h in hot water (at $60-65^{\circ} \mathrm{C}$ ) in order to increase the moisture content to greater than $30 \%$, Then paddy is steamed in order to gelatinize the starch, and dried afterwards to reduce the moisture content to $14 \%$ for safe storage or milling (Wimberly, 1983). Due to the physical and chemical changes which take place during the parboiling process, it is found that the head rice out-turn is increased by reducing the broken grain percentage, and increases the thiamin content of the grain (Otebayo et al., 2001). Further, Heinemann, et al. (2005) reported that parboiling prior to milling resulted in an $18 \%$ higher mineral retention, especially $\mathrm{K}$ and $\mathrm{P}$, than raw rice milling.

According to a study carried out using $\mu$-CT and MRI technologies to identify the effect of grain microstructure effect on cooking behaviour, it was found that the higher level of porosity within the grain reduces the cooking time (Mohoric et al., 2009). However, during parboiling the starch crystals are gelatinized and become amorphous molecules resulting in less porosity within the rice grains. Therefore, the hydration time during the cooking process increased for parboiled rice resulting in longer cooking time, leading to higher cooking energy than raw milled rice (Otebayo et al., 2001).

It is known that the household sectors utilize a large portion of energy in developing countries. Unfortunately, more than half of that amount is being used in domestic cooking (Pokharel et al., 1992 and Roy et al.,2004) was carried out a study to investigate the effect of soaking on conservation of cooking energy of one rice variety (Belleputana), in order to find the effect of soaking on cooking energy. However, in this study three soaking durations were considered instead of optimizing the soaking time and physical characteristics of grains. The objective of this study was to investigate the effect of grain shape and presoaking of parboiled rice on cooking time and cooking energy. 


\section{MATERIALS AND METHODS}

\section{Selection of paddy varieties}

Since both Long and Medium grain types are popular in different regions of the country, two popular varieties for each type Bg 360 and Bg 94-1 were selected as shown in Table 1.

Table 1. Physical dimensions of $\mathrm{Bg} 360$ and $\mathrm{Bg}$ 94-1 rice varieties according to USDA and FAO classification system

\begin{tabular}{lccccccc}
\hline $\begin{array}{l}\text { Rice } \\
\text { variety }\end{array}$ & $\begin{array}{c}\text { Length } \\
(\mathbf{m m})\end{array}$ & $\begin{array}{c}\text { Width } \\
(\mathbf{m m})\end{array}$ & $\begin{array}{c}\text { Length/Width } \\
\text { ratio }\end{array}$ & \multicolumn{2}{c}{$\begin{array}{c}\text { Classification based on } \\
\text { size (Length) }\end{array}$} & \multicolumn{2}{c}{$\begin{array}{c}\text { Classification } \\
\text { according to shape } \\
\text { (Length/Width) }\end{array}$} \\
& & & & USDA & FAO & USDA & FAO \\
\hline Bg 94-1 & 6.58 & 1.87 & 3.658 & Medium & Long & Slender & $\begin{array}{c}\text { Slender } \\
\text { Bg 360 }\end{array}$ \\
\hline
\end{tabular}

\section{Determination of soaking duration for parboiled rice}

A simple empirical two parameter equation first proposed for modeling the water vapour absorption of milk powder and soaking (Peleg, 1988) was employed to determine the sorption curves of each factorial combination. This model also proved with satisfactory results in a study conducted for modeling water absorption kinetics during vacuum soaking of rice (Bello et al., 2008). This model is now referred to as Peleg model and relates the instantaneous moisture content with the initial moisture content and the soaking time as follows;

$$
\mathrm{m}(\mathrm{t})=\mathrm{m}_{\mathrm{o}}+\frac{\mathrm{t}}{\mathrm{k}_{1}+\mathrm{k}_{2} \mathrm{t}}
$$

Where, the variation of moisture content is denoted as $\mathrm{m}(\mathrm{t})$, in decimal dry basis, with the time $\mathrm{t}$, and $\mathrm{m}_{\mathrm{o}}$ is the initial moisture content (decimal dry basis) and $\mathrm{k}_{1}, \mathrm{k}_{2}$ are constants.

Then Two $100 \mathrm{~g}$ samples from both Bg 94-1 and Bg 360 parboiled rice were soaked in 300 $\mathrm{mL}$ of distilled water at room temperature (27 \pm 2$)$ and at atmospheric pressure. Subsequently the samples weren drawn at $15 \mathrm{~min}$ intervals for $2.5 \mathrm{~h}$ and another three samples were taken at $30 \mathrm{~min}$ intervals afterwards. After the surface moisture of the rice kernels was removed they were kept in oven at $120{ }^{\circ} \mathrm{C}$ for $24 \mathrm{~h}$ (AOAC, 2000) and dry weights were measured in order to calculate the moisture content at each time period and to derive the moisture curves.

Then the hydration curves were plotted and the Peleg's model was fitted to the derived hydration curves using the curve fitting tool box of Matlab $7^{\circledR}$ (2004) numerical computing software. According to Peleg's model, highest moisture content (equilibrium moisture content) is achieved when $t \ddagger \infty$. Since prolonged soaking enhances microbial fermentation resulting in odour development and also since longer soaking durations are impractical, maximum allowable soaking time was set as $2.5 \mathrm{~h}$. In order to provide equal conditions for both samples, the variety in which the sorption process is slower, was only allowed to hydrate for $150 \mathrm{~min}$ and the moisture content at that particular time was calculated using the Peleg model. The required soaking duration was calculated for the other variety taking the above moisture content as a constant. 


\section{Optimization of the rice to water ratio}

Four parboiled rice samples of $250 \mathrm{~g}$ each from $\mathrm{Bg} 94-1$, and $\mathrm{Bg} 360$ were cooked in an electric rice cooker (Mitsubishi electric rice cooker-Model NJ-Z18T) using four different rice to water volume ratios; $1: 2,1: 2.5,1: 3: 1$ and 1:3.5. Few kernels were taken out after the rice was cooked, and pressed between two glass plates and observed for an opaque core. The optimum rice to water ratio was determined based on the minimum rice to water ratio which produced cooked rice without having an opaque core when pressed.

\section{Experimental design and statistical analysis}

After gathering preliminary data on the optimum rice-water ratio and hydration duration for parboiled rice of both varieties, a two factor factorial experiment was set up considering the rice variety (with two levels as Bg94-1 and Bg 360) and the pre-cooking condition (soaked and un-soaked conditions as two levels) as the considered factors. Four replicates were tested for each of the factor combinations and the collected data was analyzed using General Linear Model (GLM) procedure in Minitab $15^{\circledR}$ (2006) statistical software.

\section{Measurement of cooking time and cooking energy of rice}

According to the rice to water optimization trial, it was found that 1: 2.5 was the optimum volume ratio for parboiled rice of both $\mathrm{Bg} 94-1$, and $\mathrm{Bg} 360$ varieties. Then, $300 \mathrm{~mL}$ of rice samples were cooked using $750 \mathrm{~mL}$ of distilled water for each of the four factor combinations. Electric rice cooker operated at $110 \mathrm{~V}$ was coupled to main power supply through a step down transformer $(230 \mathrm{~V} \ddagger 110 \mathrm{~V})$ and a $110 \mathrm{~V}$ digital watt meter (Model P4400 KILL A WATT ${ }^{\mathrm{TM}}$ ) (Fig. 1). Power consumption was recorded until the rice cooker switches off after rice was cooked.

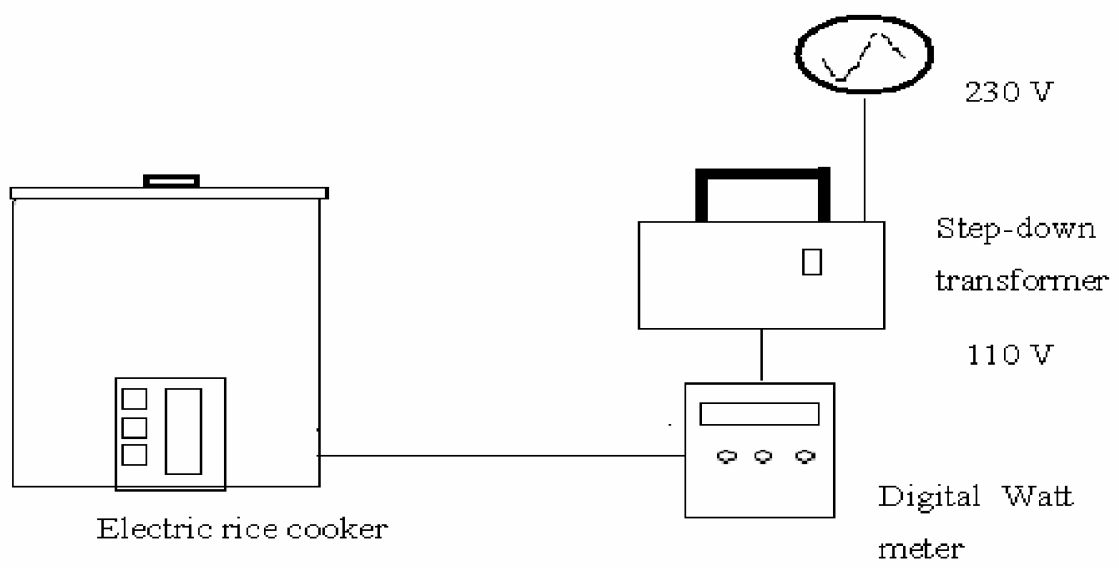

Fig. 1. Instrumentation setup for the measurement of cooking energy of rice

\section{RESULTS AND DISCUSSION}

\section{Hydration curves of polished rice}

For both slender and medium shaped rice varieties, the hydration curves exhibited the characteristic moisture absorption curves, showing a rapid increase during the initial stages 
of soaking followed by a reduction in the absorption rate until they reach equilibrium moisture content as illustrated in Fig. 2. The results of the curve fitting procedure are reported in Table 2, including the Peleg's coefficients and correlation coefficient $\left(R^{2}\right)$. The correlation coefficients of 0.987 and 0.993 as well as the lower residual sums of squares and mean relative deviation modulus $(\mathrm{P} \leq 10)$ show a good fit of Peleg's model for both slender and medium varieties of parboiled rice.

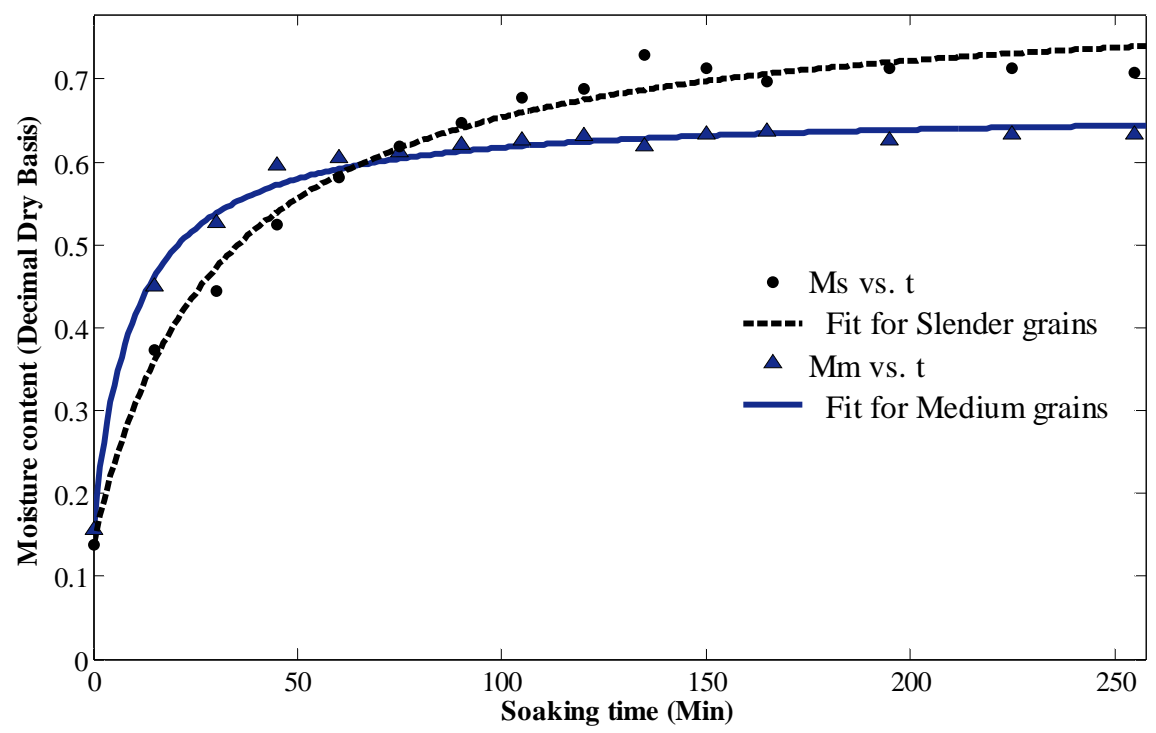

Fig. 2. Hydration curves of parboiled rice of both slender grain variety and the medium grain variety at room temperature $\left(27 \pm 2^{\circ} \mathrm{C}\right)$ and at atmospheric pressure

Table 2. Results of the curve fitting procedure for hydration curves including Peleg's constants $\left(k_{1}, k_{2}\right)$ and correlation coefficient, $R^{2}$

\begin{tabular}{lccccc}
\hline Variety & $\mathbf{k}_{\mathbf{1}}$ & $\mathbf{k}_{\mathbf{2}}$ & $\mathbf{R}^{2}$ & $\mathbf{R S S}$ & $\mathbf{P}$ \\
\hline Slender (Bg 94-1) & $45.28 \pm 7.58$ & $1.485 \pm 0.074$ & 0.987 & 0.005143 & 2.38 \\
Medium (Bg 360) & $19.32 \pm 3.34$ & $1.973 \pm 0.047$ & 0.993 & 0.001661 & 1.53 \\
\hline
\end{tabular}

However, the hydration curve of parboiled, medium grain variety shows a steeper increase compared to the observed absorption curve of the slender grain variety. Therefore, the slender grain variety takes a longer time to reach the equilibrium moisture content at room temperature and at atmospheric pressure, than the medium grain variety.

Optimum soaking periods of $150 \mathrm{~min}$ for slender variety and 44 min for medium grain variety were selected for constant wetting percentage of $86 \%$ as illustrated in Table 3.

Table 3. Optimized soaking times and the moisture contents after soaking

\begin{tabular}{lccccc}
\hline Variety & $\mathbf{M}_{\mathbf{0}}$ & $\mathbf{T}(\mathbf{m i n})$ & $\mathbf{M C}(\mathbf{t})$ & $\mathbf{M}_{\mathbf{e}}$ & wetted\% \\
\hline Slender (Bg 94-1) & 0.138 & 150 & 0.698 & 0.811 & $\mathbf{8 6}$ \\
Medium (Bg 360 ) & 0.156 & 44 & 0.570 & 0.663 & $\mathbf{8 6}$ \\
\hline
\end{tabular}




\section{The General linear model procedure for the cooking energy and cooking time}

According to the study, the rice to water volume ratio of 1:2.5 was identified as the optimum condition for cooking both rice varieties.

The mean energy and the mean time requirements for each and every factor combination are illustrated in Figures 3 and 4.

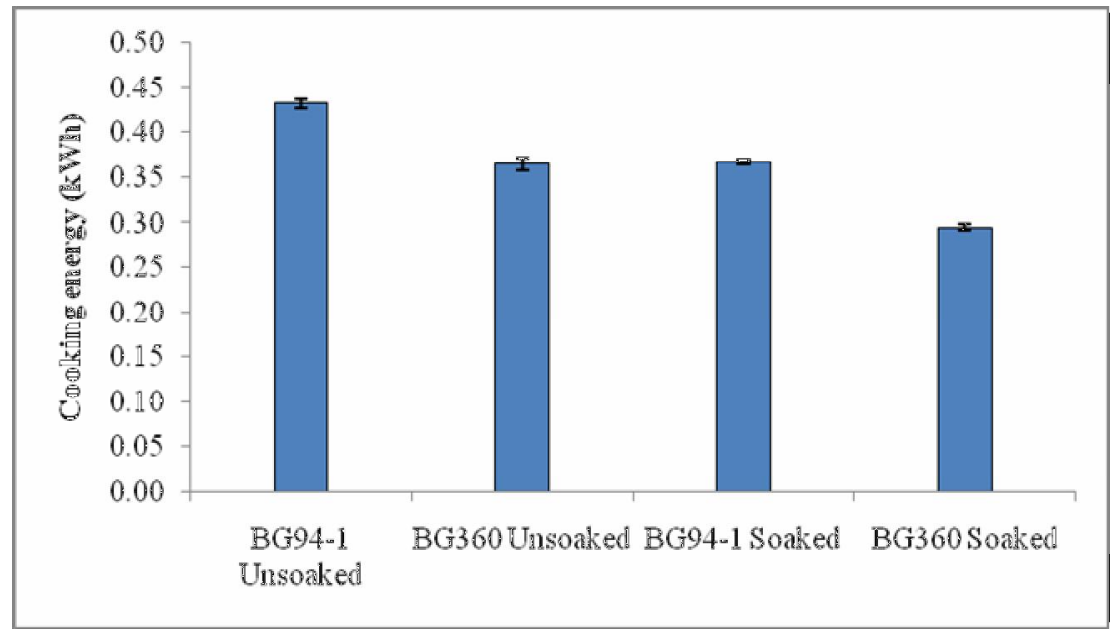

Fig. 3. Mean cooking energy values for all factor combinations

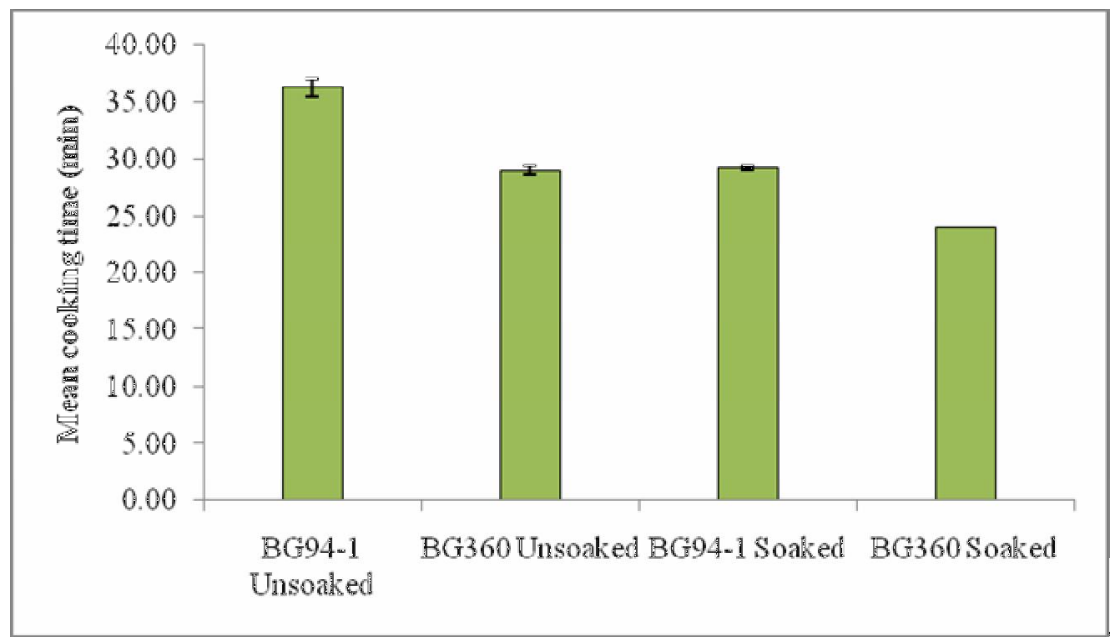

Fig. 4. Mean cooking times for all factor combinations

According to the ANOVA (Table 4), the main effects of both factors, rice variety and the pre-cook condition were found significant $(\mathrm{p} \leq 0.05)$ while the interaction effect was not significant for cooking energy $(\mathrm{p}>0.05)$ as illustrated by the two parallel lines in the interaction plot of the rice variety (level 1-Slender grain variety, and level 2- Medium grain variety) and the pre-cook condition (level1 - Un-soaked, level 2- soaked for optimum duration) vs. cooking energy as shown in Fig. 5. 
Table 4. Analysis of variance for cooking energy, using adjusted sums of squares for tests

\begin{tabular}{lcccccc}
\hline Source & DF & Seq SS & Adj SS & Adj MS & F & p \\
\hline Variety & 1 & 0.020 & 0.020 & 0.020 & 247.580 & 0.000 \\
Pre-Cook Condition & 1 & 0.018 & 0.018 & 0.018 & 230.210 & 0.000 \\
Variety*Pre-Cook Condition & 1 & 0.000 & 0.000 & 0.000 & 0.320 & 0.584 \\
Error & 12 & 0.001 & 0.001 & 0.000 & & \\
Total & 15 & 0.039 & & & & \\
\hline
\end{tabular}

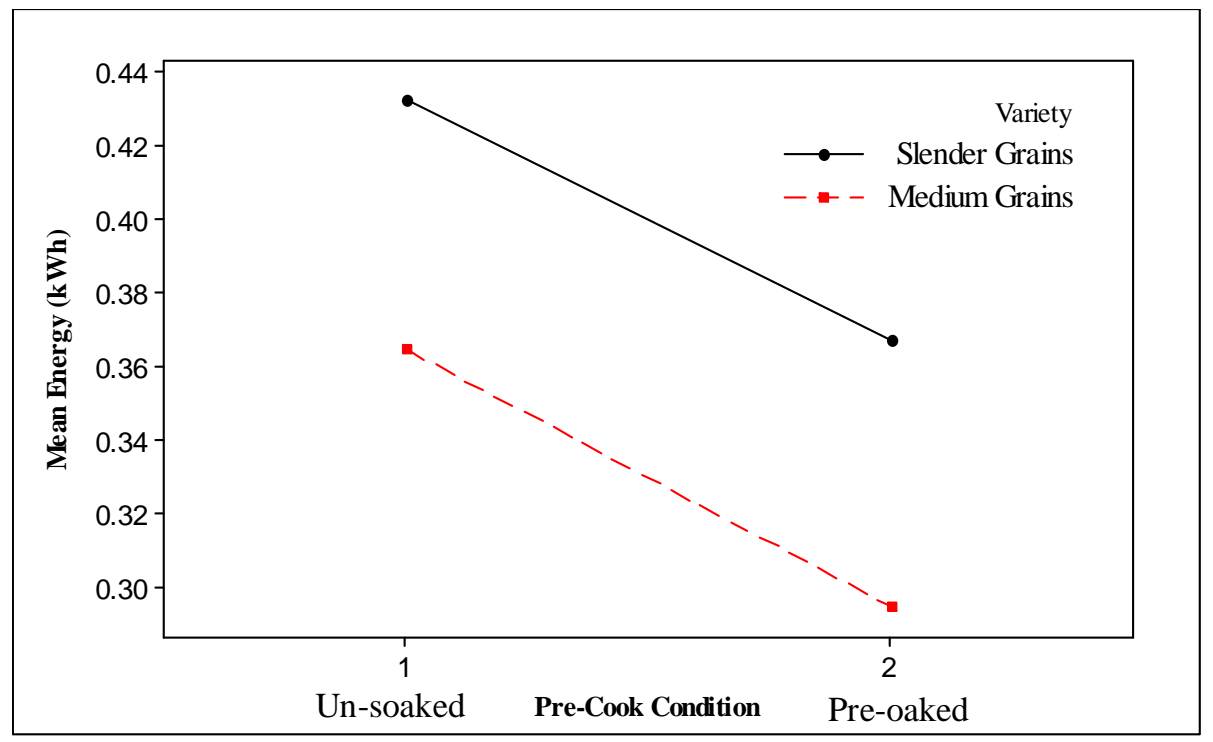

Fig. 5. Interaction plot of rice variety and pre-cook condition for cooking energy

Further, the ANOVA for GLM revealed that the main effects of both the factors, rice variety and the pre-cook condition were significant $(p \leq 0.05)$ while the interaction effect was not significant $(p>0.05)$ even though mild interaction was shown in the interaction plot (Table 5 and Fig. 6).

Table 5. Analysis of variance for cooking time, using adjusted sums of squares for tests

\begin{tabular}{lcccccc}
\hline Source & DF & Seq SS & Adj SS & Adj MS & F & p \\
\hline Variety & 1 & 156.250 & 156.250 & 156.250 & 163.040 & 0.000 \\
Pre-Cook Condition & 1 & 144.000 & 144.000 & 144.000 & 150.260 & 0.000 \\
Variety*Pre-Cook Condition & 1 & 4.000 & 4.000 & 4.000 & 4.170 & 0.064 \\
Error & 12 & 11.500 & 11.500 & 0.960 & & \\
Total & 15 & 315.750 & & & & \\
\hline
\end{tabular}




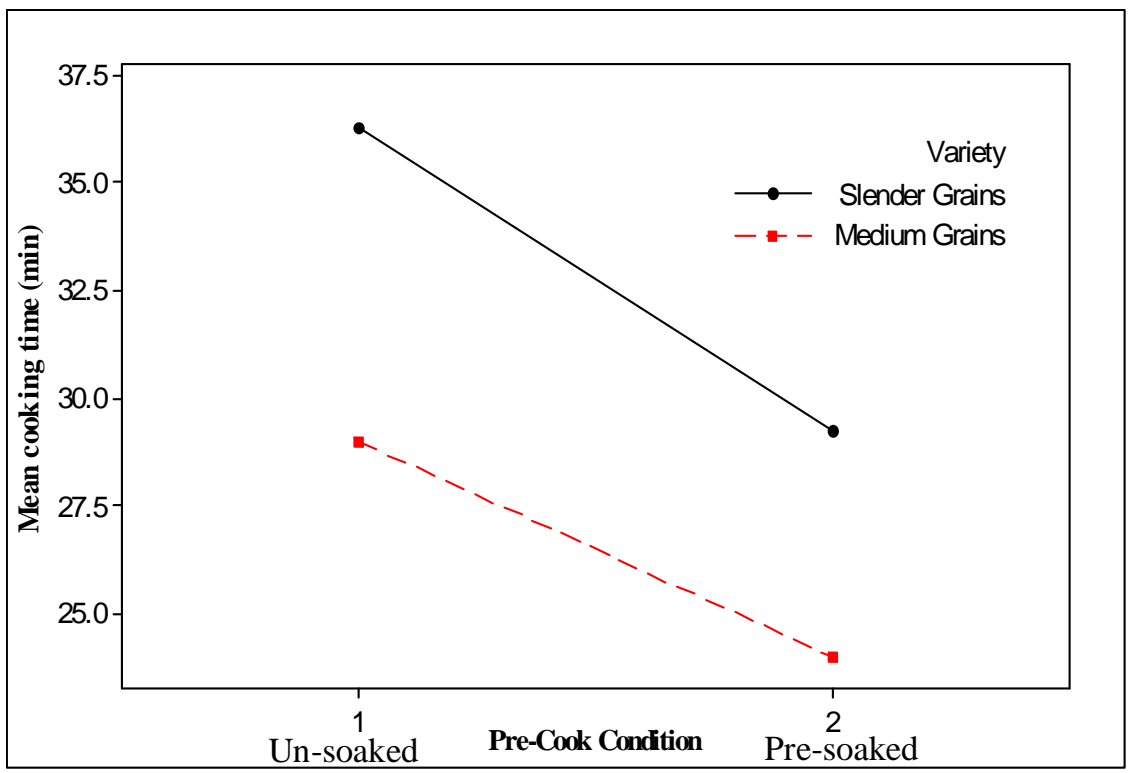

Fig. 6. Interaction plot of rice variety and pre-cook condition for cooking time

Das et al (2006) recorded that prior soaking reduces the energy consumption and cooking time during normal cooking, while pre-soaking did not contribute to the energy conservation in the case of controlled cooking in electric rice cooker. Soaking rice prior to cooking, an established energy saving practice, resulted in energy savings to the extent of $5-11 \%$ in normal cooking and $3-18 \%$ in controlled cooking and also pre-soaking shows only a marginal reduction (Lakshmi et al., 2007).

However, according to Roy et al. (2004), cooking of milled raw and parboiled rice by adopting the pre-soaking method for $60 \mathrm{~min}$ in an electric rice cooker reduced the cooking energy of cooked rice (66\% moist) by $4 \%$ and 6 to $11 \%$ respectively, although, information on grain type and saturation level was limited in all above studies. However, according to the results of this experiment, pre-soaking reduced the cooking energy requirement by $16.9 \%$ for parboiled rice for both varieties which is in agreement with Roy et al. (2004) up to a certain extent. This may be due to the uniformity of heat and mass transfer during cooking in the pre-soaked rice grains as reported by Chakkaravarthi et al. (2008). Further, pre-soaking reduced the cooking time by $18.4 \%$ in comparison with un-soaked rice. Most importantly, the medium shaped grain variety has significantly lower cooking energy $(17.5 \%)$ and cooking time $(19.1 \%)$ than the slender (longer) grain variety. Therefore, soaking prior to cooking and consumption of medium shaped rice varieties reduced cooking energy requirement of parboiled rice.

\section{CONCLUSIONS}

The optimum rice to water ratio for cooking both slender and medium rice varieties is $1: 2.5$. The medium shaped rice variety was found to reduce cooking energy by $17.5 \%$ and cooking time by $19.1 \%$ compared to slender rice variety. Pre-soaking for $150 \mathrm{~min}$ for Slender grains (Bg 94-1) and 44 min for Medium grains (Bg 360), prior to cooking, reduced both cooking 
energy and cooking time by $16.9 \%$ and $18.4 \%$, respectively compared to conventional unsoaked cooking.

\section{ACKNOWLEDGMENT}

The authors are grateful to Dr. K. S. P. Amarathunga, Head, Department of Agricultural Engineering and Dr. J. Mannapperuma, of the Board of Study in Agricultural Engineering, Postgraduate Institute of Agriculture, University of Peradeniya for providing instrumentation and technical support to conduct this study.

\section{REFERENCES}

Ameresekere, R. V. W. E. (1984). Interaction between agriculture, nutrition, and food science in Sri Lanka. In: Achaya, K. T. (Ed.) Interfaces between agriculture, nutrition, and food science. The United Nations University. Tokyo, Japan.

AOAC (2000) Official methods of analysis. $17^{\text {th }}$ Ed, Gaithersburg, MD, USA.

Bello, M. O. Tolaba, M. P. and Suarez, C. (2008). Hydration kinetics of rice kernels under vacuum and pressure. Int. J. of Food Eng. 4 (4).

Chakkaravarthi, A. Lakshmi, S. Subramanian, R and Hegde (2008). Kinetics of cooking unsoaked and presoaked rice. J. of Food Eng. 84, 181-186.

Childs, N. (2009). Rice situation and outlook yearbook. market and trade economics division, economic research service, U.S. Department of Agriculture.

Das, T. Subramanian, R. Chakkaravarthi, A. Singh, V. Ali, S. Z. and Bordoloi, P. K. (2006). Energy conservation in domestic rice cooking. J. of Food Eng. 75, 156-166.

Department of Agriculture, (2008). Api wawamu Rata Nagamu - Rice sector development in Sri Lanka 2008-2010 [online]. [Accessed on 14.06.2010] Available at http://www.agridept.gov.lk/content/admin/pdf/Rice.pdf

Heinemann, R. J. B., Fagundes, P.L., Pinto, E. A., Penteado, M.V.C. and Marquez, U. M. L. (2005). Comparative study of nutrient composition of commercial brown, parboiled and milled rice from Brazil. J. of Food Comp. Analysis 18, 287-296.

IRRI, (2008). Responding to the rice crisis how IRRI can work with its partners. International Rice Research Institute, Philippines. pp 1-10,

Lakshmi, S. Chakkaravarthi, A. Subramanian, R. and Singh, V. (2007). Energy consumption in microwave cooking of rice and its comparison with other domestic appliances. J. of Food Eng.78, 715-722.

Mohoric, A. Vergeldt, F. Gerkema, E. van Dalen, G. van den Doel, L. R. van Vliet, L. J. Van As, H. van Duynhoven, J. (2009). The effect of rice kernel microstructure on cooking behaviour: A combined l-CT and MRI study. Food Chem. 115 (2009). 1491-1499. 
Nguyen, V.N. (2002). Rice production, consumption and nutrition pp 1-8. In: The Secretariat of the International Rice Commission, FAO Rice information. Food and Agriculture Organization of The United Nations., Rome, Italy.

Otegbayo, B. O., Osamuel, F., and Fashakin, J. B. (2001). Effect of parboiling on physicochemical quality of two local rice varieties in Nigeria. J. of Food Technol. in Africa. 6(4), 130-132.

Peleg, M. (1988). An empirical model for the description of moisture sorption curves. J. of Food Sci. 53, 1216-1219.

Pokharel, S., Chandrashekar. M. and Robinson, J. B. ( 1992). Interfuel and intermode substitution for cooking. Energy 17, 907-918.

Roy, P. Shimuzu, N. and Kimura, T. (2004). Energy conservation in cooking of milled raw and parboiled rice. Food Sci. and Technol. Res. 10 (2), 121-126.

Vaughan, D. A., Lu, B. R, and Tomooka, N. (2008). The evolving story of rice evolution. Plant Sci. 174(4), 394-408.

Weligamge, P. (2003). Characteristics of rice consumption in Sri Lanka: Prospects for sustainability of the domestic rice production. In Proc. of the 9th International Conference on Sri Lankan Studies "Sri Lanka at Crossroads; Continuity and Change", 10. University of Ruhuna. Matara, Sri Lanka.

Wimberly, J.E. (1983). Technical Hand Book for the Paddy. Rice postharvest industry in developing countries, International Rice Research Institute, Manila, Philippines. pp. 101, 103, 114. 